\title{
AUTUMN IN SASKATCHEWAN A Photo Essay
}

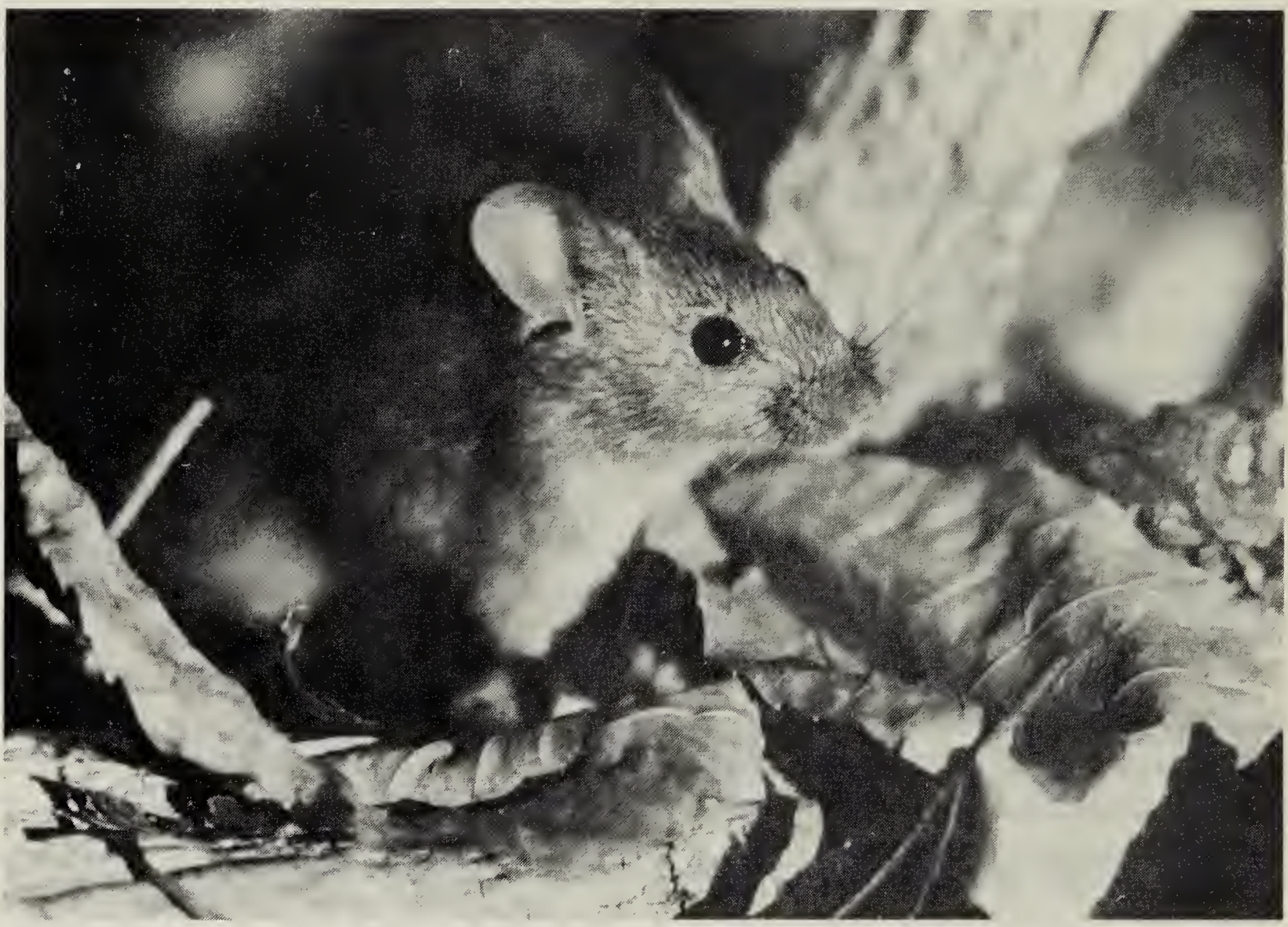

Deer Mouse

Wayne Lynch

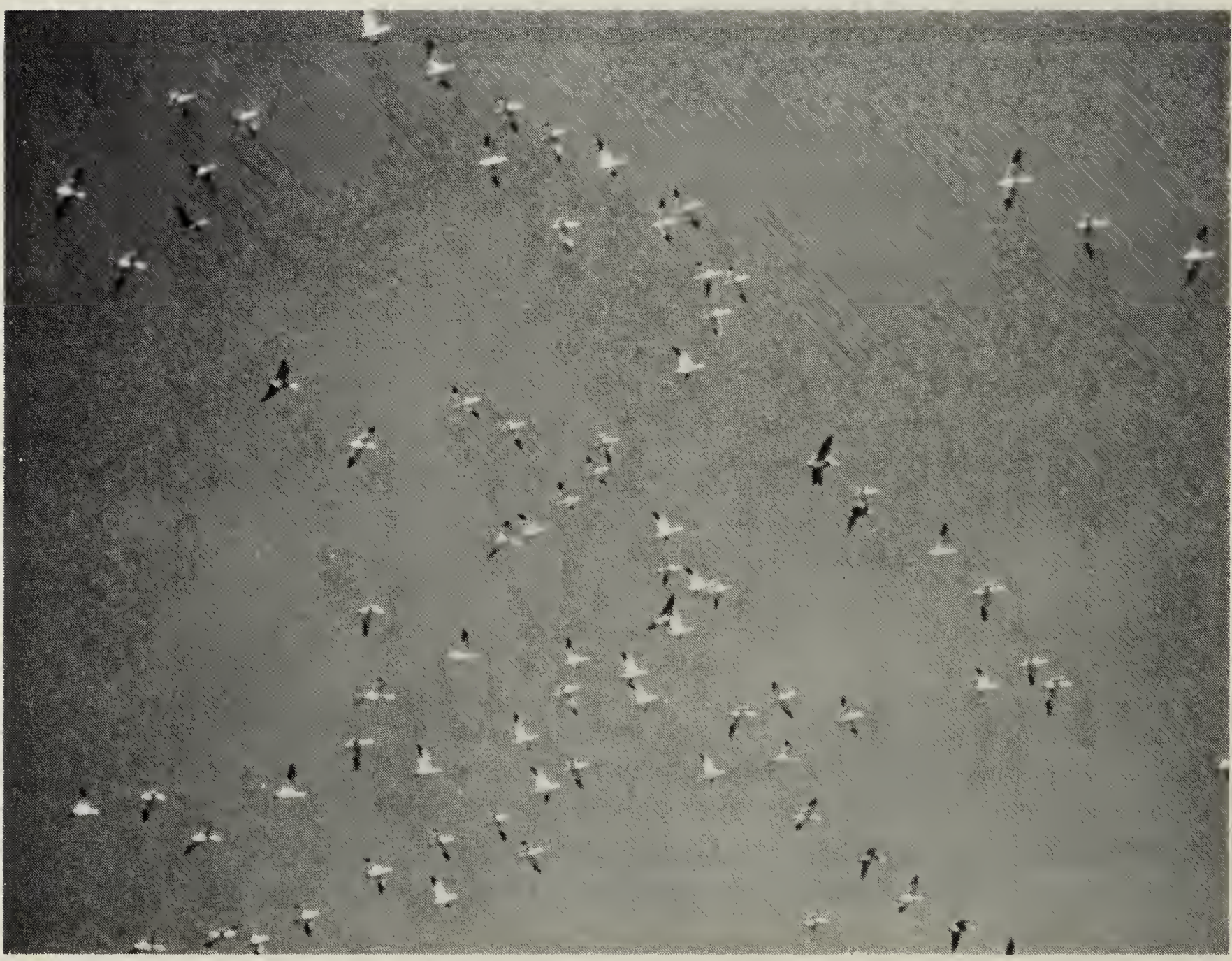




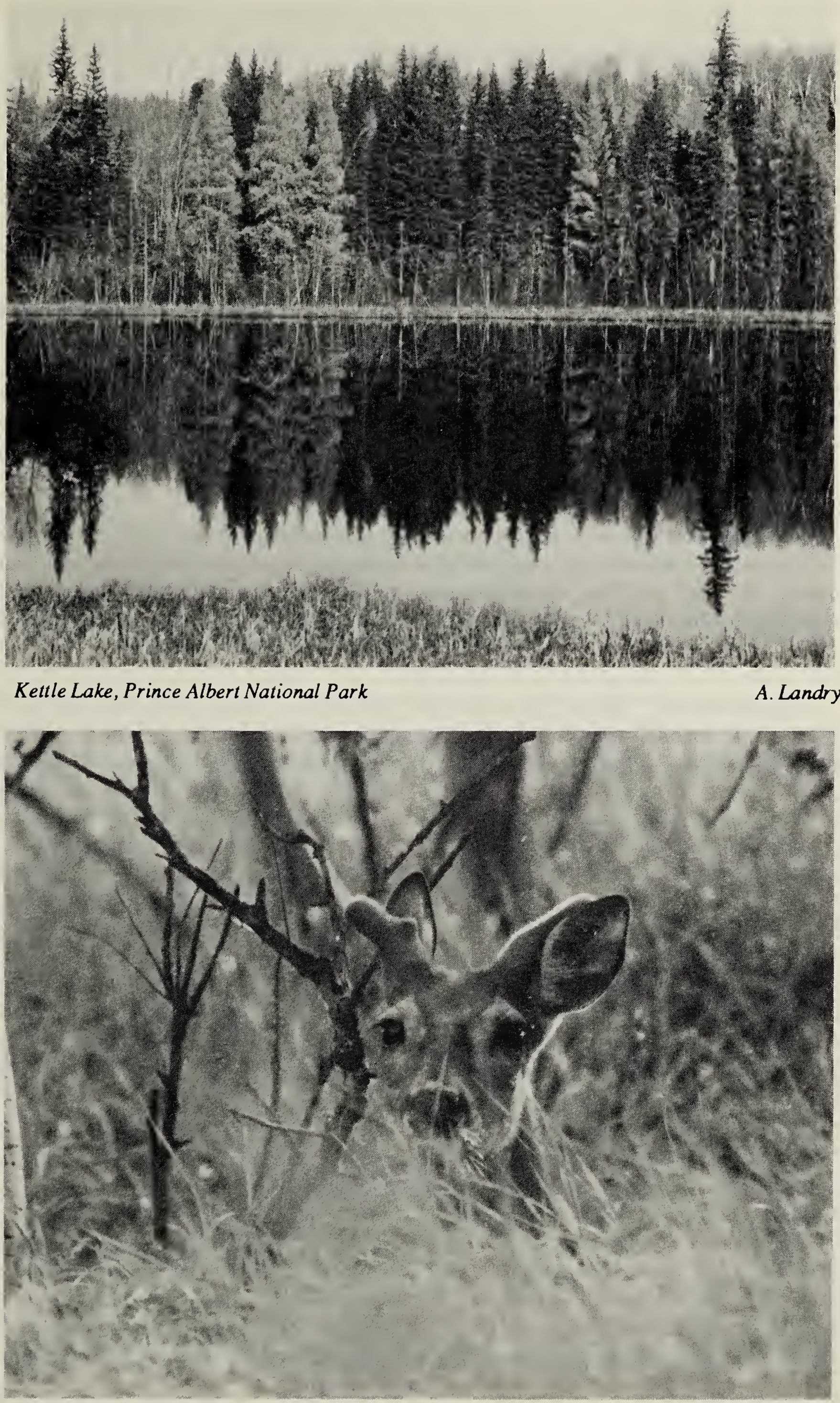

White-Tailed Deer near Chelan, Sask.

Four Winds 